\title{
Archaeological Surveys on the German North Sea Coast Using High-Resolution Synthetic Aperture Radar Data
}

\author{
Martin Gade $^{1 *}$, Jörn Kohlus ${ }^{2}$, and Cornelia Kost ${ }^{3}$ \\ ${ }^{1}$ Institut für Meereskunde, Universität Hamburg, 20146 Hamburg, Germany - Martin.Gade@ uni-hamburg.de \\ ${ }^{2}$ LKN Schleswig Holstein, Nationalparkamt, 25832 Tönning, Germany \\ ${ }^{3}$ Wördemanns Weg 23a, 22527 Hamburg, Germany
}

KEYWORDS: Wadden Sea, storm surge, SAR archaeology, TerraSAR-X, cultural traces, settlements

\begin{abstract}
:
We show that high-resolution space-borne Synthetic Aperture Radar (SAR) imagery with pixel sizes well below $1 \mathrm{~m}^{2}$ can be used to complement archaeological surveys in areas that are difficult to access. After major storm surges in the $14^{\text {th }}$ and $17^{\text {th }}$ centuries, vast areas on the German North Sea coast were lost to the sea. Areas of former settlements and historical land use were buried under sediments for centuries, but when the surface layer is driven away under the permanent action of wind, currents, and waves, they appear again on the Wadden Sea surface. However, the frequent flooding and erosion of the intertidal flats make any archaeological monitoring a difficult task, so that remote sensing techniques appear to be an efficient and cost-effective instrument for any archaeological surveillance of that area. Space-borne SAR images clearly show remnants of farmhouse foundations and of former systems of ditches, dating back to the $14^{\text {th }}$ and to the $16^{\text {th }} / 17^{\text {th }}$ centuries. In particular, the very high-resolution acquisition ('staring spotlight') mode of the German TerraSAR/ TanDEM-X satellites allows for the detection of various kinds of residuals of historical land use with high precision. In addition, we also investigate the capability of SARs working at lower microwave frequencies (on Radarsat-2) to complement our archaeological survey of historical cultural traces, some of which have been unknown so far.
\end{abstract}

\section{INTRODUCTION}

In Medieval times, the German North Sea coastline was very different from how it is today: the North Frisian islands did not yet exist, but were still what was called the 'Uthlande' (outer lands) and what was part of, or connected with, the mainland (Behre, 2009). Vast areas along the coast were dominated by swamps, marshes, and swamp forests, which often made any settlements difficult or impossible. In the sparse settlements on the German North Sea coast houses were often built on dwelling mounds, protected by small dikes (the latter being called 'summer dikes', because they could effectively provide protection against high water only during summer, when there are usually no storms). Systems of drainage ditches were built to remove the water from the farmlands, thereby allowing for any kind of agriculture.

On January 16, 1362, after more than 24 hours of severe westerly storm, an immense storm tide flooded the coast, causing the small dikes to break at many places, and eventually causing the death of a great number of cattle and men. As a result of that storm surge, which is known in history as the Saint Marcellus' Flood or 'Grote Mandrenke' ('great drowning of men'), huge land areas were lost to the sea, and they haven't been diked ever since (compare the upper and middle panels of Figure 1). Thereafter, it took a long time until new dikes were built to protect the remaining marsh land. The new farmland was characterized by wider plots of land, the dikes enclosed larger polders than in the centuries before, and farmhouses on terps were connected by narrow lanes.

Another major storm surge occurred on October 11, 1634, again killing cattle and men, after the dikes had broken at many places. This second 'Grote Mandrenke' (also known as Burchardi Flood) hit the area of North Frisia in an economically weak period, after the plague had caused many deaths only about 30 years before. The island of Strand, in the center of the North Frisian coast, was cut into parts by the flood (compare the middle and lower panels of Figure 1), thereby destroying farmland, farms, and whole villages. The Burchardi Flood is still the most-known storm surge in history in the area of the North Frisian Wadden Sea.
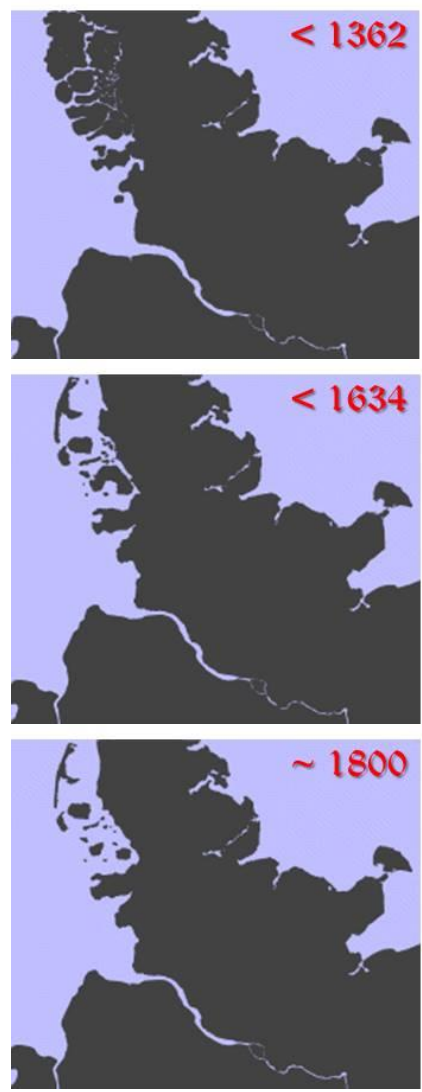

Figure 1. Changes in the German North Sea coastline during the past 700 years, after Behre (2009).

\footnotetext{
* Corresponding author
} 
Over the following centuries, great parts of this former agricultural area have been buried under muddy and sandy sediments, which nowadays form the German Wadden Sea. This area is being flooded, and falls dry, once during each tidal cycle, thereby making archaeological excavations very difficult. However, under the permanent action of the tidal forces the muddy and sandy marine sediments are partly driven away, and traces of former peat digging, drainage systems, and settlements appear again on the surface (Bantelmann, 1967). Since those areas are difficult to reach, and thus to observe from ground, airborne sensors have proven to be advantageous for a systematic observation of the residuals of those historic places (Gade and Kohlus, 2011, 2015). Their use, however, is costintensive, which makes high-resolution space-borne sensors an alternative source of data that can be used by archaeologists for their frequent surveillance of the area (Gade et al., 2014; Gade and Kohlus, 2016).

\section{REGION OF INTEREST}

A map of our area of interest is shown in Figure 2, with the location of the Synthetic Aperture Radar (SAR) image in Figure 5 inserted. The area of interest lies in the center of the North Frisian Wadden Sea, i.e. in an area, which was most affected by the major storm surges in the $14^{\text {th }}$ and $17^{\text {th }}$ centuries (see Figure $1)$.

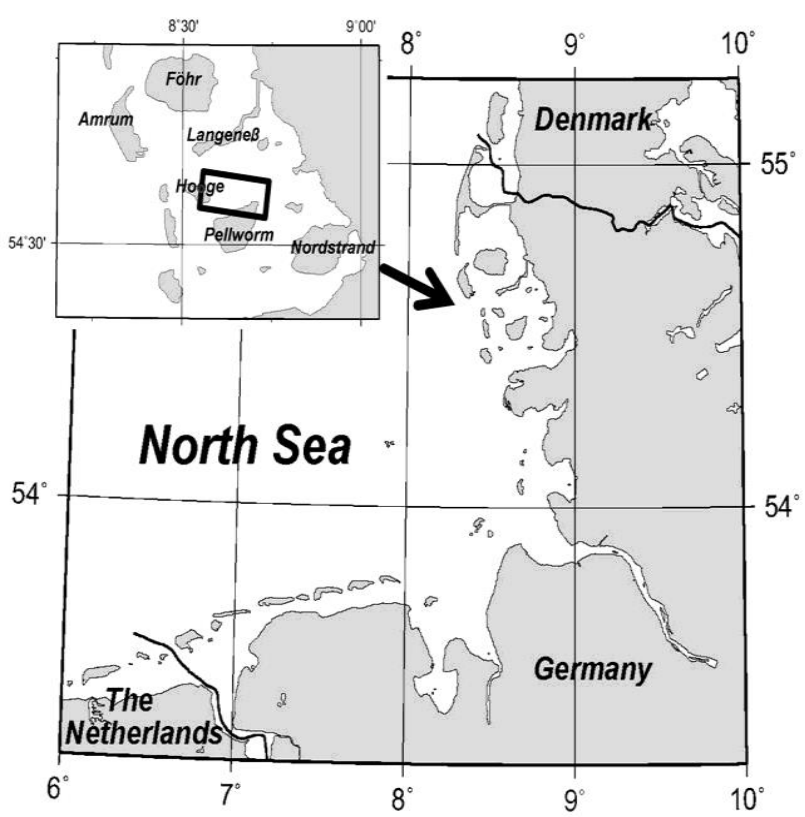

Figure 2. Area of interest on the German North Sea coast. The black rectangle in the close-up on the upper left marks the location of the SAR image shown in Figure 3.

The locations of all (known) cultural traces are depicted in Figure 3, where the green background color marks the islands of Pellworm (bottom) and Hooge (left) and the yellow background color the former island of Strand (cf. Figure 1). Two red squares mark areas of former settlements that were investigated in greater detail, 'Waldhusen' (lower left) and 'Bupsee' (upper right), where remnants of former ditches and lanes and of former settlements, respectively, can be delineated on SAR imagery.

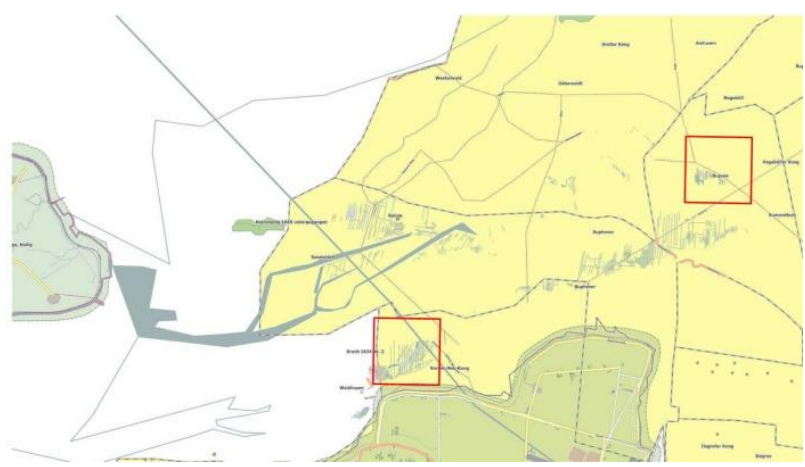

Figure 3. Map showing locations of residuals of former landuse, in the region of interest. Inserted are two red squares that denote the locations of the SAR image details shown in Figure 6 and in Figure 8, respectively. Map: C. Kost.

\section{SYNTHETIC APERTURE RADAR DATA}

A total of 26 TerraSAR-X/TanDEM-X images acquired in highresolution spotlight mode between 2008 and 2014 form the basis for our systematic analyses of SAR signatures of historical land use. The pixel sizes of all images were on the order of $1 \mathrm{~m}^{2}$, or even below, thereby allowing for the detection of fine structures that can be attributed to remnants of narrow ditches or settlements. Those images are complemented by older Radarsat2 SAR images acquired in UltraFine mode $\left(1 \mathrm{~m}^{2}\right.$; upper panel of Figure 4$)$ and TerraSAR-X spotlight mode imagery $\left(1 \mathrm{~m}^{2}\right.$; lower panel of Figure 4), and by TerraSAR-X/TanDEM-X acquisitions in the new 'staring spotlight' mode, with extremely fine pixel sizes of $0.3 \mathrm{~m} \times 0.3 \mathrm{~m}$ and below.

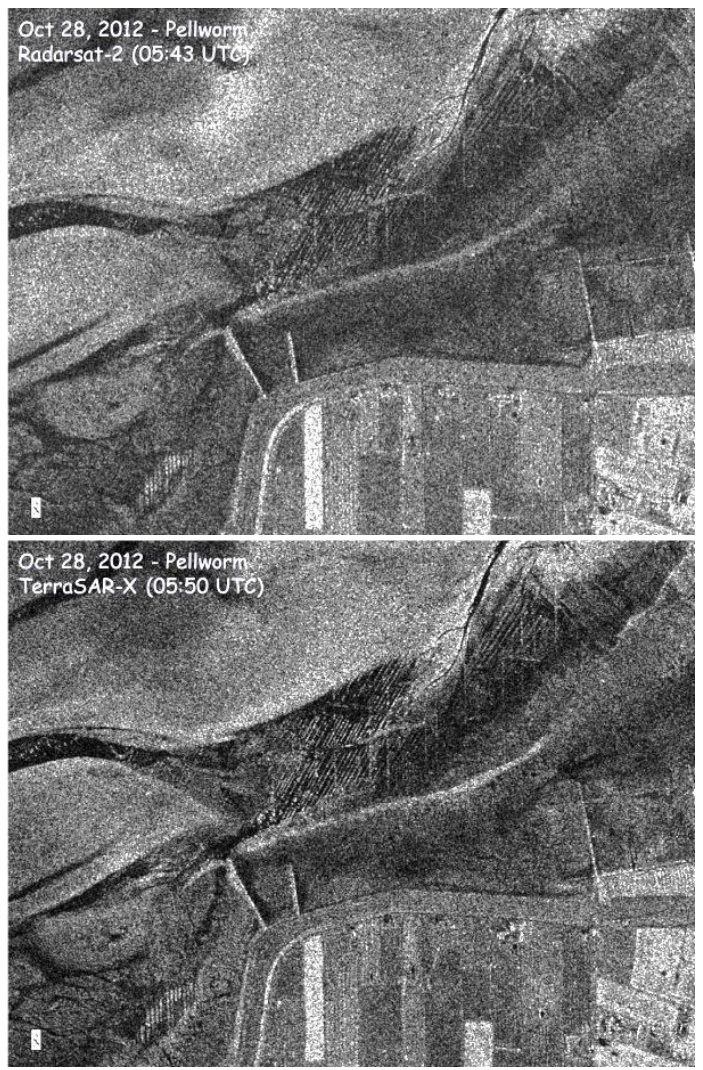

Figure 4. Radarsat-2 (upper) and TerraSAR-X (lower) SAR images of the same spot, north off Pellworm, acquired on 28 October 2012. The diagonal lines in the images' centers are remnants of historical ditches. 
The two SAR images in Figure 4 were acquired on the same day, 28 October 2012, only 7 minutes apart, by Radarsat-2 (upper panel) and TerraSAR-X (lower panel), both with pixel sizes of $1 \mathrm{~m} \times 1 \mathrm{~m}$. They show the same area, north off Pellworm, containing the lower left red square in Figure 3. The diagonal parallel lines in the images' centers are caused by remnants of historical ditches that were buried for centuries under the sandy sediment. These are examples of SAR images that, for the first time, demonstrated that cultural traces can be seen by space-borne SAR (operating at different microwave bands).

A TerraSAR-X image $(11.6 \mathrm{~km} \times 5.2 \mathrm{~km})$ of that area, acquired on December 12, 2012, (at 05:33 UTC, 18 minutes after low tide), is shown in Figure 5. The islands of Pellworm and Hooge can be seen in the lower and left parts of the image, respectively, and tidal channels and creeks show up dark, because of the low wind speed during image acquisition $(4 \mathrm{~m} / \mathrm{s}$, blowing from SE; the radar backscattering mainly depends on the roughness of the water surface; therefore, a flat surface at low wind speeds causes low radar backscatter and, thus, dark image areas). The bright features in the right half of the image mark edges of tidal creeks and dry, sandy sediments (Gade et al., 2008), but are not of interest herein. However, in the two $(1.0 \mathrm{~km} \times 1.0 \mathrm{~km})$ areas marked by the white squares, we found fine, linear structures, which are due to remnants of former land use (before the storm surge of 1634).

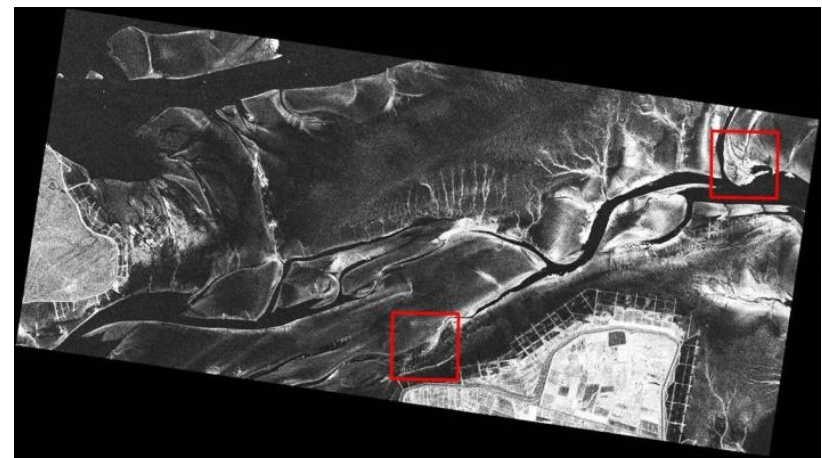

Figure 5. TerraSAR-X image of the area of interest, north of Pellworm and east of Hooge. The image was acquired on 12 December 2012. The red squares denote the same locations as in Figure 3. () DLR 2012.

\section{CULTURAL TRACES ON SAR IMAGERY}

Intertidal flats are highly morphodynamic, and when the muddy and sandy marine sediments of the flats' upper layer are moved away, banks of peat, old clay, and remnants of farmland and settlements appear again on the dry-fallen surface. Moreover, the deposition of fine sediments along those morphologically harder structures can help pronouncing them, thereby making them (better) visible in aerial and satellite imagery. Analyzing the high-resolution SAR imagery we found at several places fine linear structures, which are clearly anthropogenic.

\subsection{Settlements}

Figure 6 contains $1000 \mathrm{~m} \times 1000 \mathrm{~m}$ details of two TanDEM-X images acquired in staring spotlight mode on November 19, 2014, at 17:01 UTC (upper panel; 26 minutes after low tide, $3 \mathrm{~m} / \mathrm{s}$ wind from easterly directions) and on January 20, 2015, at 05:50 UTC (lower panel; 37 minutes before low tide, $1.3 \mathrm{~m} / \mathrm{s}$ wind from easterly directions), respectively, and shows examples of such structures. The location of these $1 \mathrm{~km}^{2}$ details is marked by the upper right square in Figure 5. The very fine pixel sizes of $26 \mathrm{~cm} \times 26 \mathrm{~cm}$ and $28 \mathrm{~cm} \times 28 \mathrm{~cm}$, respectively, allow imaging of residuals of historical land use (houses, ditches, lanes), which usually are too narrow to be delineated on SAR imagery of conventional resolution (with pixel sizes on the order of $10 \mathrm{~m}$ ).
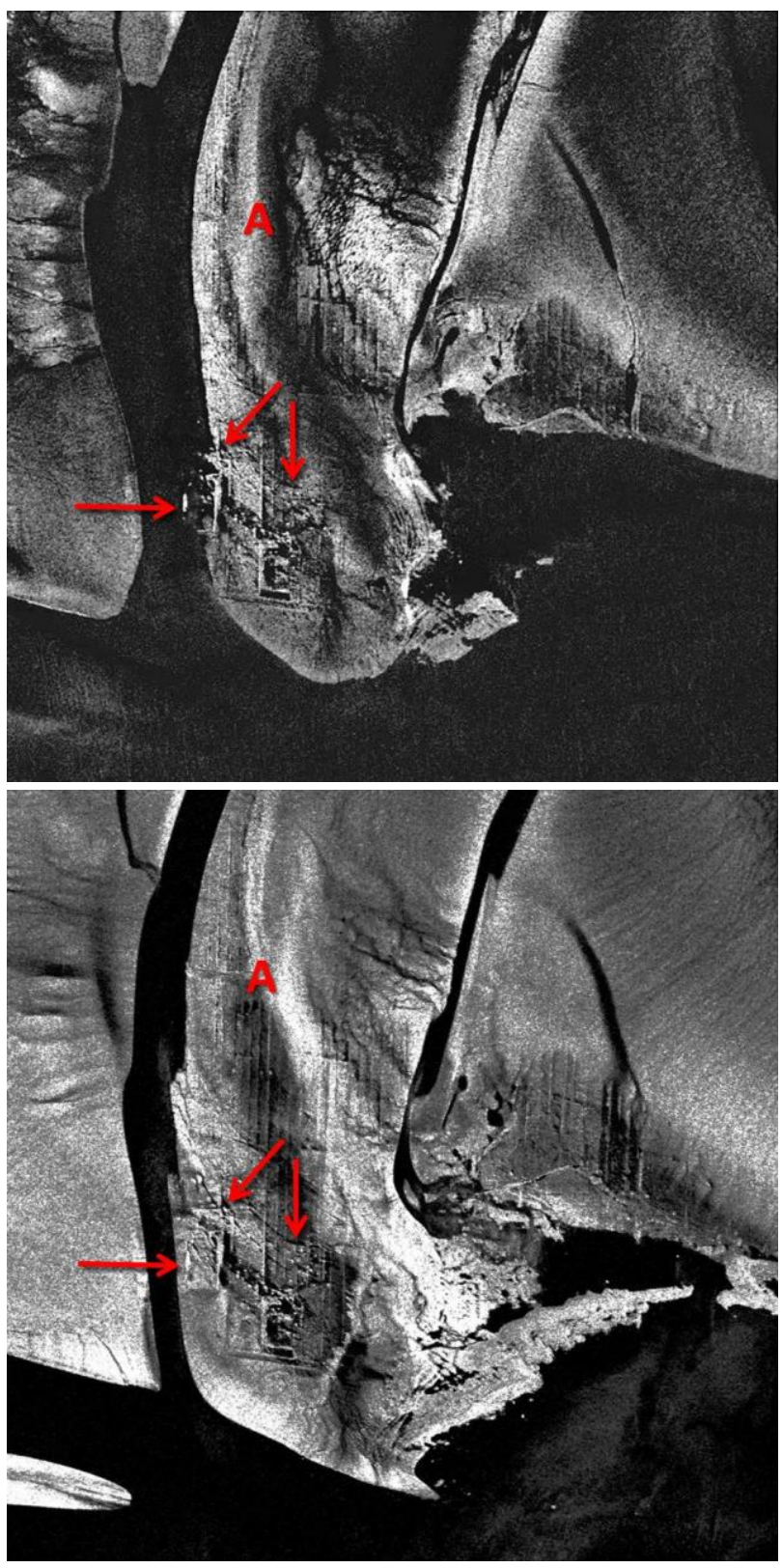

Figure 6. Subsection $(1000 \mathrm{~m} \times 1000 \mathrm{~m})$ of two TanDEM-X staring spotlight scenes acquired on 19 November 2014 (upper) and 20 January 2015 (lower), north of Pellworm. The linear structures are cultural traces. The letter (A) is explained in the text, the arrows are inserted for comparison with Figure 7. (C) DLR 2014, 2015.

Clearly visible are linear and rectangular structures in both lower left image centers, close to the tidal creek, along with groups of parallel vertical lines at different locations in both image centers. The mean distance between those parallel lines is about $15 \mathrm{~m}$, thus indicating that they are remnants of former ditches and drainage channels. In both SAR images the letter (A) marks the same location; note that the parallel vertical lines 
to the south and south-west of this location are visible only in the younger SAR image (lower panel), whereas a diffuse bright band in the older SAR image (upper panel), left of (A), indicates that this area was still covered by sandy sediments in November 2014. This comparison illustrates the strong morphodynamics on intertidal flats, and also demonstrates the need for a frequent monitoring of those archaeological sites.

Figure 7 shows an aerial photograph of the same intertidal flat north-east of Pellworm, taken on July 29, 2009, at low tide. Here, it is obvious that the linear structures origin from foundations of former settlements. In addition, several dark spots are visible, which origin from former wells, pits, cisterns, etc. Those spots can also be found on SAR imagery (as bright spots, though; see Figure 6), if the spatial resolution is high enough (in SAR images of lower resolutions they could easily be confused with speckle noise typical for SAR imagery). For an easier comparison with the above SAR images three arrows marking the same spots have been included in both the aerial photograph (Figure 7) and the second SAR image (lower panel of Figure 6). Also visible is the sandy sediment, under which those structures were buried for long, and which was driven apart by the action of currents and waves. A close comparison of the aerial photograph with the high-resolution SAR images reveals that, during the (more than) five years between the two kinds of acquisitions, parts of the residuals were already lost, due to the permanent erosion, sedimentation, and morphological changes.

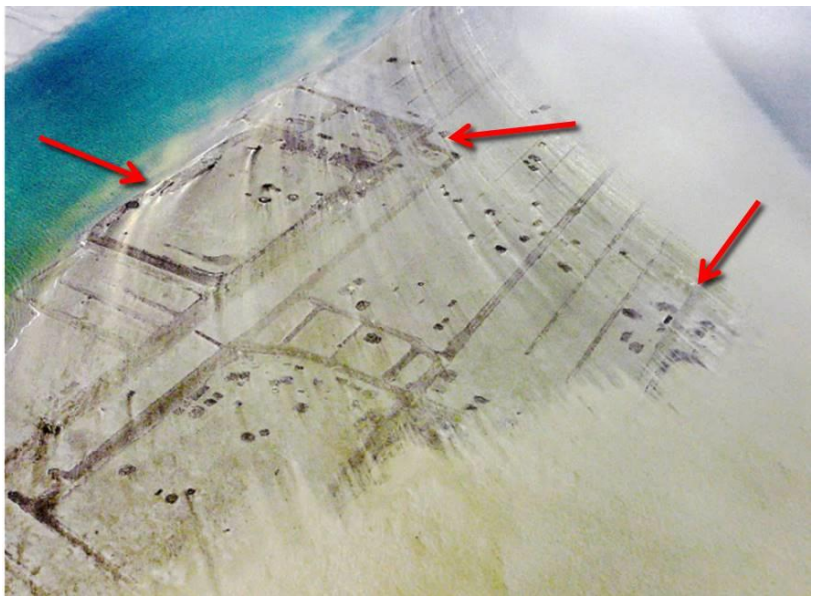

Figure 7. Aerial photograph of exposed intertidal flats north of Pellworm, taken in July 2009. Residuals of former settlements, close to a tidal creek (upper left), can be clearly seen. The arrows were included for easier comparison with the SAR image shown in Figure 6. Photograph: B. Hälterlein, LKN.

\subsection{Drainage Systems and Lanes}

Another example of very high resolution SAR imagery of archaeological sites is shown in Figure 8. The small section (again, $1000 \mathrm{~m} \times 1000 \mathrm{~m}$, corresponding to the lower left square in Figure 5) of a TanDEM-X staring spotlight scene was acquired on November 21, 2014, at 05:41 UTC (low tide; $2 \mathrm{~m} / \mathrm{s}$ wind from easterly directions) and shows many bright and dark parallel lines all over the image center. The distance of those lines is between $10 \mathrm{~m}$ and $20 \mathrm{~m}$, again, indicating that they are remnants of a former mesh of draws and ditches built for the drainage of the farmland. The ditch residuals are marked by denser (harder) sediment causing higher surface roughness which, in turn, results in higher radar backscattering. However, we also note that, once the space in between is partly filled with sandy sediments, some of the lines may also appear dark (seen in the image center of Figure 8).

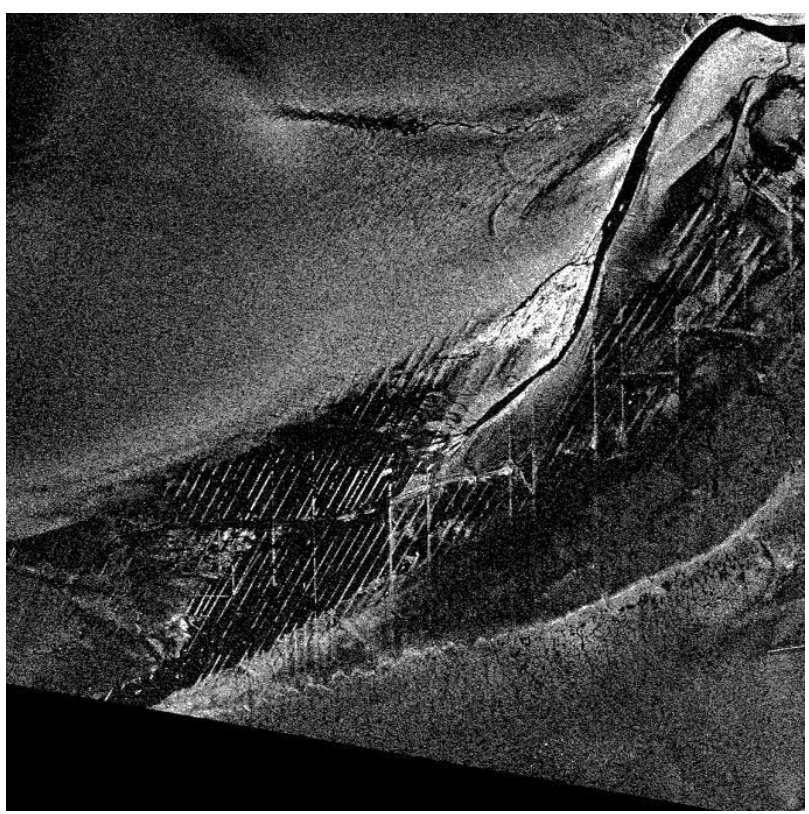

Figure 8. Subsection $(1000 \mathrm{~m} \times 1000 \mathrm{~m})$ of a TanDEM-X staring spotlight scene acquired on November 21, 2014, north of Pellworm island and showing in its lower center the same area as in Fig. 9. () DLR 2014.

Figure 9 shows a photograph taken during low tide on May 14 2009, from a dike on the northern coast of Pellworm island. In the image center dark parallel structures can be delineated, which correspond to those seen on the SAR images. Clearly visible are the differences in sediment composition of the linear structures and the surrounding sandy flats. Also visible is remnant water in between the dark lines (and in several puddles all over the place), which results in a stronger contrast between the parallel bright lines and the dark area in between (Figure 8).

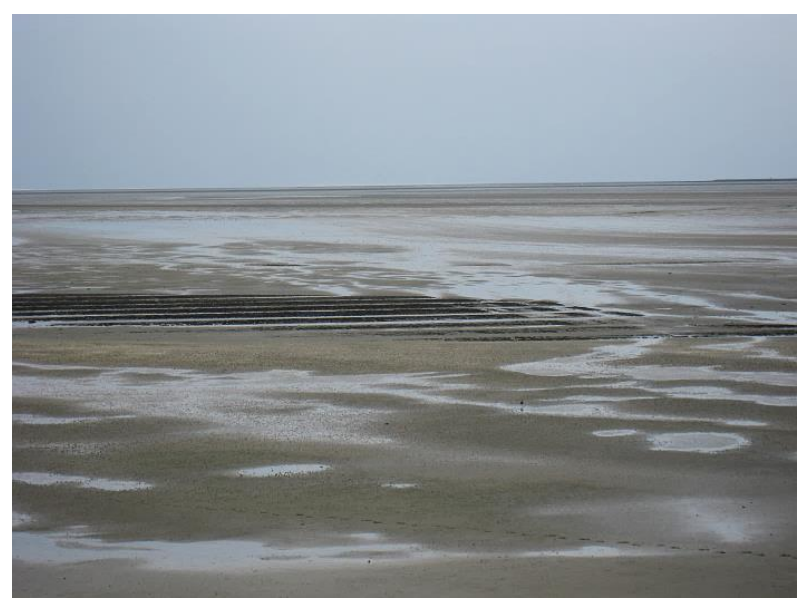

Figure 9. Photograph taken from a dike on Pellworm island and showing manifestations of historical land use as dark parallel lines. Photograph: M. Gade.

Finally, Figure 10 shows a reconstruction of a historical lane, with ditches on either sides, which can be found on the intertidal flats north of Pellworm and which may cause structures like those observed in the SAR imagery. Residuals of fossil farmland structures, mostly of ditches, but also of lanes or 
dikes, cannot be observed through their relief of less than 10 $\mathrm{cm}$. Instead, it is the sediments on the lost pastures that are different from those in the linear structures of ditches. Typical Wadden sediments on the flat sand banks consist of marine fine sand, which had been the basic compound of the old marsh land and which is still a major part of the coastal environment. In contrast, the surface of the fossil ditches is different: in the center pillow-like sediments can be found, while the ditch edges are often stabilized by fossil roots and other plant material connected with the sediment (Figure 10). This causes narrow ridges of only $10 \mathrm{~cm}$ to $20 \mathrm{~cm}$ width, which can still be found today and which show up on SAR imagery, if its spatial resolution is high enough.

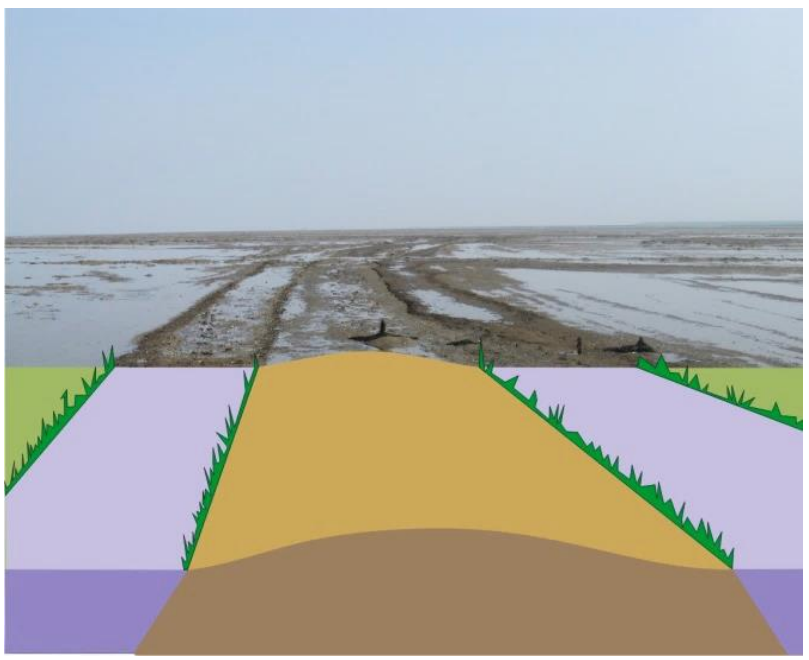

Figure 10. Reconstruction of a historical lane with ditches on either side. Photograph and sketch: J. Kohlus.

\section{CONCLUSIONS}

High-resolution SAR images can be used to complement archaeological surveys on intertidal flats on the German North Sea coast. Here, signatures of both former settlements and remnants of former systems of ditches and of peat cutting, dating back to periods before major storm surges in the $14^{\text {th }}$ and $17^{\text {th }}$ centuries, can be found on high-resolution TerraSAR/TanDEM-X images. In this respect, best results were obtained (i.e., strongest and clearest signatures were found) when SAR images acquired in the new 'staring spotlight' mode, with pixel sizes on the order of $0.1 \mathrm{~m}^{2}$, were used.

In many cases, the observed signatures of former ditches are due to different sediment types, which in turn are due to the actual ditch morphology. Fossil roots and other organic material may result in denser and harder sediments, which may be directly sensed by the space borne SAR, or which may cause additional sedimentation (i.e., deposition of sandy sediments) that can be seen on SAR imagery. We also note that different sediments may cause different biological productivity, and are therefore often marked by benthic organisms, which may cause different surface roughness patterns. It is those patterns that are sensed by the high-resolution X-Band SAR.

The archaeological sites presented herein have already been subject to previous studies (Gade and Kohlus, 2011, 2015, 2016; Gade et al., 2014). However, the new high-resolution TerraSAR-X acquisition mode ('staring spotlight') allows for the detection of various kinds of residuals of historical land use, some of which have been unknown so far.

\section{ACKNOWLEDGEMENTS}

The work presented herein was partly funded by the German Ministry of Economy (BMWi) under contract 50 EE 0817, 'DeMarine-U / SaMoWatt', TSX data were provided by DLR under contracts COA0994 and COA2500.

\section{REFERENCES}

Bantelmann, A., 1967. Die Landschaftsentwicklung an der schleswig-holsteinischen Westküste. Wachholtz, Neumünster, $97 \mathrm{pp}$.

Behre, K.-H., 2009. Landschaftsgeschichte Norddeutschlands: Umwelt und Siedlung von der Steinzeit bis zur Gegenwart. Wachholtz, Neumünster, 308 pp.

Gade, M., and Kohlus, J., 2011. Archeological Sites on Intertidal Flats in the German Wadden Sea'. Proceedings of the 4th TSX Science Team Meeting, DLR Oberpfaffenhofen, Germany, 14-16 February 2011, DLR Publications.

Gade, M., and Kohlus, J., 2015. SAR Imaging of Archaeological Sites on Dry-Fallen Intertidal Flats in the German Wadden Sea. Proceedings of the International Geoscience and Remote Sensing Symposium (IGARSS) 2015, Milan, Italy.

Gade, M., and Kohlus, J., 2016. After the Great Floods: SARDriven Archaeology on Exposed Intertidal Flats. Proceedings of the ESA Living Planet Symposium 2016, Prague, Czech Republic.

Gade, M., Alpers, W., Melsheimer, C., and Tanck, G., 2008. Classification of sediments on exposed tidal flats in the German Bight using multi-frequency radar data. Remote Sensing of the Environment, 112, pp. 1603-1613.

Gade, M., Melchionna, S., Stelzer, K., and Kohlus, J., 2014. Multi-Frequency SAR Data Help Improving the Monitoring of Intertidal Flats on the German North Sea Coast. Estuarine, Coastal and Shelf Science, doi: 10.1016/j.ecss.2014.01.007. 